\title{
CORRECTION
}

\section{Correction to: Changes in expression of lysosomal membrane proteins in leucocytes of cancer patients treated with tyrosine kinase inhibitors}

\author{
N. Pastvova ${ }^{1} \cdot$ J. Havlasek ${ }^{1} \cdot$ P. Dolezel ${ }^{1} \cdot$ K. Kikalova $^{1} \cdot$ H. Studentova ${ }^{2} \cdot$ A. Zemankova ${ }^{2} \cdot$ B. Melichar ${ }^{2} \cdot$ P. Mlejnek $^{1}$ (D
}

Published online: 7 May 2021

๑) Springer-Verlag GmbH Germany, part of Springer Nature 2021

\section{Correction to: Cancer Chemotherapy and Pharmacology https://doi.org/10.1007/s00280-021-04266-6}

In the Original publication of the article, the graphical abstract was not included. The graphical abstract is available in this correction. The original article has been corrected.

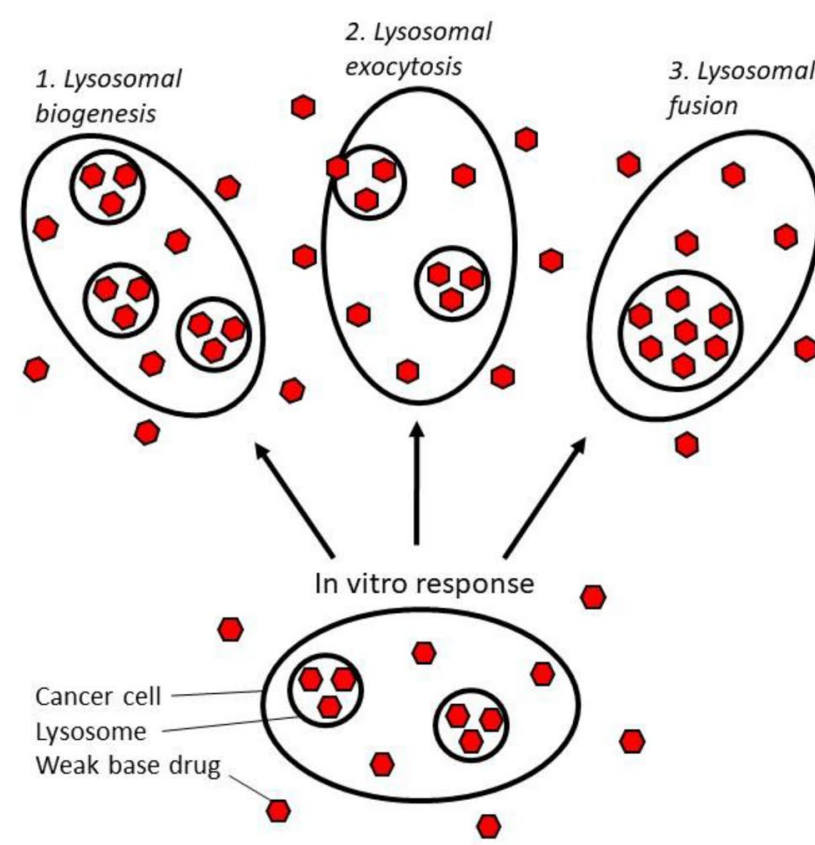

Lysosomal weak base drug sequestration
Publisher's Note Springer Nature remains neutral with regard to jurisdictional claims in published maps and institutional affiliations.

The original article can be found online at https://doi.org/10.1007/ s00280-021-04266-6.

P. Mlejnek

mlejnek_petr@volny.cz

1 Department of Anatomy, Faculty of Medicine

and Dentistry, Palacky University Olomouc, Hnevotinska 3,

Olomouc 77515, Czech Republic

2 Department of Oncology, Palacky University Medical School and Teaching Hospital, Olomouc, Czech Republic 